\title{
The Consumer in a Globalizing World: Insights from a Multi- Level Marketing Firm
}

\author{
Nnamocha Obiageli Angela \\ Department Of Marketing, \\ Imo State University, Owerri, Nigeria
}

\begin{abstract}
As noted by Kamila, Mask and Michael (2014), the phenomenon of globalization is of paramount importance for today's marketing practitioners. Globalization reducesthe gap between nations, occasioned by vast advancements in technology, transportation and communication, while ease of exchange and access to information and world markets are the fruits/dividends of globalization. As globalization increases, people across various nations tend to become similar in their purchases and consumption behavior (Mohamed et al 2013). Interestingly, these people have diverse orientations and culturesand yet, they tend to behave alike in consumption contexts. This goes to show that consumer satisfaction and value in a globalised world seem to transcend geographical horizons. As noted by Mariola and Danielak (2015), there is no single common position on how purchasing decisions are determined by global trends and to what extent are the results of culture and conditioning. Consumers having access to communication and technology, therefore, automatically conduct more research, rationally searching for the best deals. In this study, the researcher used a combined approach, i.e. theoretical framework, empirical evidence and experimentation or primary data generation through fieldwork. The sample consists of about 1,350 consumers and 150 marketers; totaling 1,500 respondents. The hypotheses of the study focus on the dual (positive and negative) effects which globalization has on both the consumers and the marketers alike, and how these would rub-off on the nation's economy. In addition to simple descriptive statistics, correlation analysis and the z-test are used in testing the data so generated.
\end{abstract}

Key Words: Globalisation, Marketing, Consumer Behaviour, Economic Transformation, SpillOver Effects

\section{INTRODUCTION}

Globalization is an economic and cultural integration, making the world a smaller unit by breaking down boundaries and barriers to commerce and information. The principal goal of globalization as focused on in this study is poverty reduction through increased access to information, funds and products by increasing employment potentials and health benefits. Economic underpinnings of globalization according to Ogungbowa and Eburajolo (2014) are the collapse of communism, the liberalization of cross-border trades, finance and labour and real time exchange of technology and information across the globe.

The researcher is of the opinion that Multi-Level Marketing transnational organizations hold the promise to these aforementioned goals of globalization. However, whereas in other traditional forms of marketing product adaptation may be practiced across geographical /national boundaries, products marketed under the MLM platform are standardized in the understanding that although people from different nations have diverse orientations and cultures, they tend to have similar values in consumption contexts. In addition, when the potentials for income and employment are available, less emphasis seems to be placed on nationality divides. 
Using EDMARK as the focus organization, this study uses a combined approach of theoretical considerations, empirical evidence and primary data collection to determine the extent to which globalization has affected Nigerians, using the five states in the south-east geo-political zone as the unit of study.This is the golden age for business, commerce and trade (Handi, 2013), therefore the need has arisen, to seek collaborations across national borders in order to actualize the promise of globalization in Nigeria.

This study is motivated by the fact that a majority of the Nigerian population are poor, using the various indices for measuring poverty. However, the eradication or at least, halving the percentage of the poor is the very first of the Millennium Development Goals (MDGs).

...the starting point for addressing the challenges of poverty is the simple and obvious observation that the primary problem of the poor is that they have a low income.... Ameel (2017).

In agreement with this, the International Labour Organization(2007) states that nothing is more fundamental to poverty reduction than the opportunity for employment of the concerned group.

As noted by Okeke and Nwankpa (2017) income security is primarily for the satisfaction of the citizen's physiological needs, especially in developing economies.

As noted by Ameel (2017), the best way to reduce poverty is to focus on raising the productive capacity of the people, not necessarily their consumption capacity. Two dimensions are discernible from this assertion: increasing the earning potentials of the poor and providing them increased access to welfare as basic services. In order to improve income earning potentials, job creation and skills acquisition are vital.

The thrust of this study is on the first component for earning potentials, which is job creation as it relates to MLM Companies and globalization.

The market for Multi-Level Marketing investment grows significantly in times of economic transition, employee displacement and the need for globalization. This is because of its promises of quick returns, part-time employment and high success rate. MLM is however considered as a variant of Direct Selling.

The World Federation of Direct Selling Agents (WFDSA) defined network selling as the marketing and selling of products and serves directly to the consumers in a face to face and in places like home, workplace and other offices other than retail sales locations.

The principal difference between multi-level marketing and direct selling is the organizational set up of the teams, as well as the method of income generation and compensation.

Multi-Level Marketing is also known as pyramid selling, structure marketing and Network Marketing. It is a form of direct selling which entails the creation and building of a network of clients who are distributors for the brand.

As noted by Pradii (n.d.), income generation in the MLM occurs when a distributor recruits other distributors, who in turn keeps recruiting others, thus extending the network, leading to the upstream distributors (up-liners) earning commissions, rebates and points. The company 
provides sales training and sales kits to the distributors, in order to teach them the art of communication, how to build and grow relationships and the potentials of success in the business. This is achieved through team meetings, seminars and conferences, as well as exclusive memberships to various achievers' clubs.Multi-Level Marketing is a business model which is anchored on links/connections between customers (up-liners and down-liners) in order to achieve sales and increase profits.

\section{Statement of Research Problem}

Nigeriaisexperiencing globalization just as all other countries of the world but the dividends of this phenomenon are far from being obvious. Although, the basis for engaging in globalization is for economic transformation, research evidence as well as observation of various economies, sometimes point to the other direction.

A major task of globalization, supported by the Millennium Development Goals (MDGs) is to reduce poverty. This can be achievable through sundry means including creation of employment and improvement in the health of citizens.

The burden of this study therefore is to ascertain how the operations of Multi-Level Marketing (MLM) organizations as well as the consumption behaviours of their product adopters, rub-off on the populace using EDMARK as a case study organization.

\section{Objectives of the Study}

To ascertain the extent to which EDMARK MLM has functioned as a driver of globalization, in terms of poverty alleviation, creation of employment and promotion of health/wellness.

\section{Research Questions}

1. What is the relationship between participation in EDMARK and employment opportunities in Nigeria?

2. To what extent is the health of the Nigerian populace improved by the consumption of EDMARK products in Nigeria?

3. To what extent does participation in EDMARK enhance poverty alleviation in Nigeria?

\section{Hypotheses of the Study}

H01: EDMARK organization has no significant influence on employment opportunities in Nigeria.

HO2: Consumption of EDMARK products has no significant effect on the health of its Nigerian consumers.

H03: Participation in EDMARK has a no significant effect on poverty alleviation in Nigeria.

\section{Scope of the Study}

The geographical scope of this study covers the five South Eastern States of Nigeria; Abia, Anambra, Ebonyi, Enugu, and Imo, while the unit scope is made up of the distributors/marketers of EDMARK as well as the consumers in this zone.

\section{Brief History of the Firm}

EDMARK group of companies established in 1984 as Ever-Dynamic Marketing is a multi-dollar company with market presence in over 25 countries.

In 2004, the company's Multi-Level Marketing arm ventured into international expansion, starting off with its first branch in Dubai, United Arab Emirates. Its presence came to Africa in 2008, when it was introduced into Ghana, while Nigeria followed suit in 2009. There are a total 
of 16 EDMARK branches in 10 African countries of Ghana, Cote D'Ivoire, Kenya, Togo, Sudan, Uganda, Burkina Faso, Ethiopia, Cameroun and Nigeria.EDMARK boasts of over 300,000 active distributors worldwide, involved in marketing their various products and this obviously qualifies the organization to be viewed as a globalization agent.

The specific attractions of EDMARK among other MLMs include the use of consumable healthy products- not drug/food supplements such as coffee, beverages, toothpaste and bathing soap, free training sessions and the 9-great bonuses in the marketing plan, consisting of retail profit 15 - 25\%, performance bonus 20 percent, manager bonus 20\%, achievement bonus $3 \%$, leadership bonus $25 \%$, travelling fund $2 \%$, year-end bonus $2 \%$, car fund $3 \%$, and house fund $2 \%$, totaling a payout of $71 \%$. This is considered to be the best in the industry, among others.

\section{THEORETICAL CONSIDERATIONS}

The benefits of globalization remain unevenly distributed in developing countries of Africa (Ajufua and Oknonkwo, 2014), so, although there are great opportunities for economic improvement, globalization benefits are not automatic.

Nistor (2007) asserts that the benefits of globalization cannot be achieved by means of a total freedom in action for the economic entities (organisations).

Therefore, it is of utmost importance to avoid the adverse effect of persistent poverty, especially in under-developed and developing countries, by encouraging non-governmental efforts at improving the economy.

The Millennium Development Goals (MDGs) are the world's time-bound and quantified targets for addressing extreme poverty in its many dimensions of income poverty, hunger, disease, lack of adequate shelter and exclusion, while promoting gender equality, education and environmental sustainability.

According to Lee (2014) developing countries such as Nigeria have suffered from persistent poverty and rising inequality along with globalization which refutes neo-classical trade theory.As noted by Graham (2004), a puzzle in the debate over globalization is the gap between economists' assessments of aggregate benefits of the process and the more pessimistic assessments of the general public.

The debate among economists on this issue claims that globalization makes the rich to become even richer, while pro-globalization enthusiasts assert that it actually helps the poor.

This disparity in opinion may be due to the differences in the appreciation, assessment and characterization of poverty by these different schools of enquiry.

Fortunately, as noted by Pranab (2006), these two schools of globalization theory are slowly developing some agreements on the potentials for co-ordination among trans-national companies and local aid groups, in helping to alleviate poverty, to improve wellness and to generate employment. This, therefore, is the basis for using EDMARK as the focus organization in this study.

Poverty is the inability to attain a minimum standard of living (WorldBank 1990), where a population or a section of population is unable to meet its bare subsistence essentials such as food, clothing and shelter (Balogun, 1999) and may be revealed in various forms such as a high 
rate of unemployment, poor health system and low life expectancy rate (Ogungbowa and Eburajolo, 2014).

\section{Empirical Evidence on the Relationship between Globalization and Economic Development}

1. Ghinimire (2006) found that globalization creates tension among nations rather than harmonize relationships between them, thus implying that it breeds poverty among the less developed nations.

2. Nnadi (2010) found that globalization has negatively influenced Nigerian economic growth leading to a decline in Foreign Direct Investment (FDI); thuslinking a positive relationship between globalization and poverty in Nigeria.

3. Oyewale and Amusat (2013) found a non-linear relationship between globalization and poverty reduction in Nigeria. In addition, they noted that the impact of globalization on poverty hinges on the extent to which the poor participates in the income-growth process.

4. Salimono (1999) found that globalization offers economies the potentials of eradicating poverty.

5. Okungbowa and Eburayolo (2014) found that globalization led to poverty reduction.

\section{Advantages of Multi-Level Marketing}

1. Anyone can take it up, as there is no educational qualification/requirement.

2. It can be held as either a full-time vacation or along-side one's main career.

3. It helps in building social contacts, leading to mutually beneficial relationships, at least in the short run.

\section{Criticisms of Multi-Level Marketing}

According to Ali (2015), the MLM business model is a market place hoax, characterized by massive failure rates. She posits that the revenue for the small number of financial manners comes from the constant enrolment of armies of losers.

In addition, Multi-Level Marketing schemes do not enjoy brand loyalty, since the major reason most people join it is to make quick money, not necessarily due to brand preference towards its products/services.

Success in any Multi-Level Marketing scheme is not easy and requires substantial effort. Evidence show that only a negligible percentage $(0.05 \%$ for Amyway and $0.3 \%$ for Nuskin) gain a majority of the company rebates. What then becomes of the vast majority of losers? It appears that their investments are used to fund the largesse of the minority who prove successful.In fact, the success of Multi-Level Marketing is not indicative of core value to the economy or customers but rather of the high levels of economic fear and insecurity prevalent in a given society.

Using the 70\% rule to determine the legality of Multi-Level Marketing business, at least 70\% of all goods sold by the Multi-Level Marketing company must be purchased by non-distributors.

\section{METHODOLOGY}

Pre-validated structured questionnaires were evenly distributed to respondents from where insights were generated. (See distribution and retrieval table in figure 1.) 
Angela, N. O. (2019). The Consumer in a Globalizing World: Insights from a Multi-Level Marketing Firm. Archives of Business Research, 7(SP), 57-

\begin{tabular}{|l|l|l|l|l|l|l|}
\hline \multirow{2}{*}{} & \multicolumn{3}{|c|}{ Marketers of EDMARK } & \multicolumn{3}{c|}{ Users of EDMARK Products } \\
\cline { 2 - 7 } & $\begin{array}{c}\text { No of Dist. } \\
\text { Questionnaire }\end{array}$ & $\begin{array}{c}\text { No of Returned } \\
\text { Questionnaire }\end{array}$ & Percentage & $\begin{array}{c}\text { No of Dist. } \\
\text { Questionnaire }\end{array}$ & $\begin{array}{l}\text { No of Returned } \\
\text { Questionnaire }\end{array}$ & Percentage \\
\hline Abia State & 30 & 23 & $\mathbf{1 5 \%}$ & 270 & 216 & $\mathbf{1 6 \%}$ \\
\hline $\begin{array}{l}\text { Anambra } \\
\text { State }\end{array}$ & 30 & 22 & $\mathbf{1 4 . 7 \%}$ & 270 & 198 & $\mathbf{1 4 . 6 \%}$ \\
\hline Ebonyi State & 30 & 16 & $\mathbf{1 1 \%}$ & 270 & 131 & $\mathbf{9 . 5 \%}$ \\
\hline Enugu State & 30 & 11 & $\mathbf{7 . 3 \%}$ & 270 & 218 & $\mathbf{1 6 . 4 \%}$ \\
\hline Imo State & 30 & 26 & $\mathbf{1 7 \%}$ & 270 & 237 & $\mathbf{1 7 . 5 \%}$ \\
\hline Total & $\mathbf{1 5 0}$ & $\mathbf{9 8}$ & $\mathbf{6 5 \%}$ & $\mathbf{1 3 5 0}$ & $\mathbf{1 1 0 0}$ & $\mathbf{8 1 \%}$ \\
\hline
\end{tabular}

In addition, informal focus group discussions in groupsof 5 persons each were conducted on a total of 15 marketers. Responses to the Likert-scale type of statements were used for correlation analysis to measure the degree of relationship between the identified variables of interest, while t-test was computed on the r-value result in order to determine the significance of such relationships.

\section{DATA ANALYSIS}

Theresponses to the questionnaire were used to analyze the hypotheses of the study.

\section{HYPOTHESIS I}

EDMARK organization has no significant influence on employment opportunity in Nigeria.

$r^{2}=0.54$

$\mathrm{r}=$ test calculated $\quad=7.030$

$\mathrm{t}=$ Test $_{\mathrm{tab}} \quad=1.966$

We therefore conclude that there is a significant relationship between EDMARK and employment opportunity in Nigeria.

\section{HYPOTHESIS II}

Consumption of EDMARK products has no significant effect on the health of its Nigerian consumers

$r^{2}=0.60$

$\mathrm{t}=$ Test calculated $\quad=5.1112$

$\mathrm{t}=\mathrm{tab} \quad=1.966$

We therefore accept $\mathrm{H}_{1}$ and conclude that the consumption of EDMARK products has a significant effect on the consumers' health.

\section{HYPOTHESIS III}

Participation in EDMARK has no significant effect on poverty alleviation in Nigeria.

$r^{2}=0.82$

$\mathrm{t}$ cal $=6.4281 \mathrm{t} \mathrm{tab}=1.966$

We therefore conclude that there is a significant relationship betweenparticipation in EDMARK and the alleviation of poverty in Nigeria.

\section{SUMMARY OF MAJOR FINDINGS OF THE STUDY}

1. The respondents identifiedfive (5) major reasons for choosing EDMARK. They include: that the EDMARK organization is transparent, stable in its compensation plan, has a guaranteed quality of its products and the company's vision and mission impactspositively on others.

2. EDMARK marketers asserted that the most attractive features were complete package (45\%), Holiday incentive (2\%) and Bonuses (18\%), as well as changing lives(4\%). 
3. 55 percent of the respondents work for EDMARK as full-time careers and $45 \%$ of the respondents have part time careers in EDMARK.

4. 73 percent of the respondents opined that the prices of EDMARK products are very high, while 27 percent think that its price is commensurate to the value of the products.

5. EDMARK products are rated to be of high quality by 82 percent of the respondents, while 18 percent rate it as average.

6. 91 percent of the respondents indicate that EDMARK organization can help to curb unemployment while 9 percent did not respond to this question.

7. Many of the respondents (45\%) indicated that the EDMARK leadership bonus is the most appealing compensation package, followed by gain-step, break-away and house fund.

8. 82 percent agree that EDMARK helps to alleviate poverty, while 18 percent did not respond to this question.

\section{SERVICE FAILURE/RECOVERY IN EDMARK}

1. Majority of the marketers (73\%) of EDMARK have not experienced a service failure, while others did not respond.

2. Of the $27 \%$ who did not respond question 1 , five percent responded that the problem was promptly resolved by EDMARK.

3. 73 percent of the respondents accepted that EDMARK customers experience a very high level of staff support always, while $7 \%$ responded to the contrary.

4. All the respondents (100\%) were in agreement that the EDMARK customer and staff support encourage job creation, customer satisfaction and retention.

\section{CUSTOMERS/USERS}

1. 33 percent of the respondents have used EDMARK products for less than 2 yrsand while 28 percent have used it for more than 5 years.

2. 30 percent of the respondents have referred several customers to use EDMARK products, based on their positive product experience.

3. 94 percent of the respondents agreed that EDMARK products are of very high quality.

4. 89 percent indicated that EDMARK products have immense health benefits.

5. 64 percent indicated that EDMARK helps to create job opportunities and so reduces the unemployment rate in Nigeria.

\section{PART B}

1. 33 percent of the respondents indicated that they valued the quality and health benefits of EDMARK products.

2. 84 percent expressed a high level of satisfaction with using EDMARK products.

3. 53 percent of the respondents reported to feel healthier with EDMARK products.

\section{PART C}

1. 44 percent of customers admitted that the price of EDMARK products is too high and they are not affordable.

2. 83 percent were indifferent on how they perceived the product-price relationship, while 11 percent accepted that it very high when compared to other competing products.

3. 44 percent of the customers accepted that the price of EDMARK products is commensurate to its product quality while $28 \%$ were indifferent to it.

4. The customers confirmed that monthly bonuses were a major incentive for them. 


\section{RECOMMENDATION}

In the light of the above-stated findings, the researcher is led to recommend that credible Multi Level Marketing networks be patronized, as they have been empirically proven to be agents of positive economic transformation. This is in order to benefit from its promise of improving the quality of life of the populace by providing gainful employment, maintaining sound health and alleviating poverty.

\section{CONCLUSION}

Brune and Garret (2004) assert that measuring the effects of globalization is notoriously difficult and contested. This is so true, as the results tend to vary across circumstances, due primarily to a non-standardization of the procedures used in assessment.

In this paper, the researcher does not presume to make uncontestable statements about these causal relationships; rather, it is an attempt to make a clearer sense of the debate over globalization issues, contexts and effects on the Nigerian consumer. This study has yielded a different, albeit complimentary picture of the effect of globalization on the various economic transformation indices of poverty alleviation, health potentials and employment opportunity from what is recorded in the literature earlier reviewed. This seems to be in agreement with the view of Parisac and Hashen (2014) that the effects of globalization depend on the economic structure of the countries.

\section{LIMITATIONS OF THE STUDY}

1. Some of the respondents were rather unwilling to participate in the survey, even after being assured of their anonymity and the strict confidentiality of the information so divulged.

2. Some of the questionnaires were poorly completed and this reduced the intended sample size of the study.

3. Only one Multi Level Marketing organization, EDMARK, was used for this study. This is because of the tight time schedule for concluding and submitting this project.

4. Only one geo-political region of Nigeria was covered in this study.

5. Some aspects of information which were considered as 'sensitive' could not be divulged by the staff and marketers of the focus organization. This, they claimed is based on their company policy as well as their code of ethics.

\section{SUGGESTED AREA FOR FURTHER STUDIES}

In view of the limitations of this study, the researcher suggests that further studies be conducted on the topic:

Aninquiry into the performance of several Multi Level Marketing organizations in Nigeria, as vehicles for actualizing the gains of globalization, in all the zones of the country.

\section{References}

Ajudua E. and O. Okonkwo (2014) An Empirical Review of Globalization and Nigerian Economic Performance. European Journal of Business and Management, Vol. 6, No. 33.

Ali Balaban (2015) The 10 Big Lies of Multi level Marketing; "Abduction by Aliens".

Ancel K. (2017) Marketing and Poverty Alleviation: The Perspective of the Poor. Markets, Globalization and Development, ISMD - International Society of Markets and Development Vol.2. No. 1.

Brune, N. and G. Garrett (2004), The Globalization Rorschach Test: International Economic Integration, Inequality and the Role of Government, Annual Review of Political Science, Vol. 8.

Ghimire, S. (2006) Effects of Globalization on Poverty. The World Resources Sustainable Economics to End Global Poverty. 
Graham, C. (2004) Assessing the Impact of Globalization on Poverty and Inequality: New Lens on a Old Puzzle , Economic and Governance Study Program, The Brooklyn

Handi, F. (2013) The Impact of Globalization on Developing Countries, Developing Country Studies, Vol. 3, No. 11. International Labour Organization (2007), Global Employment Trends Brief.

New York: Random House Trade Paperbacks.

Nistor, C. (2007), Positive and Negative Effects of globalization, Annals of University of Bucharest, Economic and Administrative Series.

Nnadi, E. (2010). The Impact of Globalization on the Nigeria Economy. UdIniProquest. Research unleashed Stores.

Okeke R. and L. Nwankpa (2017). The Accounting Fundamentals of Multi Level Marketing, Income Security and the Poverty Challenge in Nigeria.

Okungbowo, f. and Eburajolo, O. (2014) Globalization and Poverty Rate in Nigeria: An Empirical Analysis, International Journal of Humanities and Social Sciences, Vol A. No 11.

Oyewale, I. and Amusat, U. (2013), Impact of Globalization on Poverty Reduction in Nigeria. Interdisciplinary Journal of Contemporary Research in Business, Vo. 4 No 11.

Prachi, J. (n.d.) Introduction to Multi Level Marketing, Reviewed by Management Study Guide Content Team

Roos D. (2008) How Pyramd Schemes Work.

Zuckoff, M. (2006) Ponzi's Schemes - The True Story of a Financial Legend. 